Review Article

\title{
Critical Studies on Integrating Land-Use Induced Effects on Climate Regulation Services into Impact Assessment for Human Well-Being
}

\author{
Zhihui Li, ${ }^{1,2,3}$ Xiangzheng Deng, ${ }^{1,3}$ Jikun Huang, ${ }^{1,3}$ Rongrong Zhang, ${ }^{4}$ and Juan Huang ${ }^{5}$ \\ ${ }^{1}$ Institute of Geographic Sciences and Natural Resources Research, Chinese Academy of Sciences, Beijing 100101, China \\ ${ }^{2}$ University of Chinese Academy of Sciences, Beijing 100049, China \\ ${ }^{3}$ Center for Chinese Agricultural Policy, Chinese Academy of Sciences, Beijing 100101, China \\ ${ }^{4}$ Faculty of Resources and Environmental Science, Hubei University, Wuhan 430062, China \\ ${ }^{5}$ State Key Laboratory of Water Environment Simulation, School of Environment, Beijing Normal University, Beijing 100875, China
}

Correspondence should be addressed to Xiangzheng Deng; dengxz.ccap@gmail.com

Received 22 August 2013; Accepted 29 October 2013

Academic Editor: Burak Güneralp

Copyright (C) 2013 Zhihui Li et al. This is an open access article distributed under the Creative Commons Attribution License, which permits unrestricted use, distribution, and reproduction in any medium, provided the original work is properly cited.

\begin{abstract}
It is commonly acknowledged that land use changes (LUC) and climate changes have exerted significant effects on ecosystem services which are essential and vital to human well-being. Among all the services provided by ecosystem, climate regulation services are relatively sensitive to LUC and climate changes. This study aims to comprehensively review studies on the complex effects of LUC and climate changes on climate regulation services and further integrates the effects on climate regulation services into impact assessment for human well-being. In this study, we firstly introduced research efforts in which the drivers of and their corresponding effects on climate regulation services are briefly identified. Then, we explicitly reviewed the researches on the effects of LUC and climate changes on climate regulation services, especially focused on the certain methods and models used to quantify the effects on the major drivers of climate regulation services. After that, the effects of LUC and climate changes on human wellbeing via climate regulation services were revisited and commented accordingly. Finally, this paper discussed the current research gaps and proposed some research prospects in future studies.
\end{abstract}

\section{Introduction}

Land use changes (LUC) and climate changes are two major factors that result in the changes of ecosystem services [14]. Along with the socioeconomic development and emerging ecological environmental problems, global changes, and ecosystem services are becoming the research hot topics. The relationships among LUC, climate changes and ecosystem services are interlaced and complex, in which temporal and spatial variations in human-induced LUC and climate variability can result in the difference of ecosystem services [5].

Natural ecosystem delivers a lot of benefits to human beings, and these benefits are known as ecosystem services. According to the Millennium Ecosystem Assessment (2005), these ecosystem services include provisioning services such as provision of food, water, timber, fiber, and genetic resources; regulating services such as the regulation of climate, floods, disease, and water quality as well as waste treatment; cultural services such as recreation, aesthetic enjoyment, and spiritual fulfillment; and supporting services such as soil formation, pollination, and nutrient cycling [6]. Among all these services, supporting services and regulating services underpin the delivery of other service categories [7]. What is more, there often exist trade-offs between different services when humans make management choices, which can change the type, magnitude, and relative mix of services provided by ecosystems [8]. However, people generally prefer provisioning and cultural services over regulating services [9] thus tend to undervalue regulating services. Consequently, decision-makers often ignore these regulating services in ways that will seriously undermine the long-term existence 
TABLE 1: Direct drivers of changes in climate regulation and their corresponding effects, adapted from [18].

\begin{tabular}{lll}
\hline Category of drivers & Change of drivers & Effect on climate regulation services \\
\hline $\begin{array}{l}\text { Habitat change: } \\
\text { land and sea use }\end{array}$ & $\begin{array}{l}\text { Productive area: expansion, conversion, and } \\
\text { abandonment (agriculture, forestry) }\end{array}$ & $\begin{array}{l}\text { Affects carbon sinks and existing stores, greenhouse gas } \\
\text { (GHG) emissions, albedo and evapotranspiration, shade, } \\
\text { and shelter } \\
\text { Affects soil carbon stores, GHG emissions } \\
\text { Affects soil carbon stores, albedo, shade, shelter, local } \\
\text { temperatures, and humidity }\end{array}$ \\
$\begin{array}{lll}\text { Pollution and } \\
\text { nutrient }\end{array}$ & $\begin{array}{l}\text { Pollution emissions and deposition } \\
\text { Nutrient and chemical inputs }\end{array}$ & $\begin{array}{l}\text { Affects aerosol sources (soot) } \\
\text { Affects GHG emissions }\end{array}$ \\
$\begin{array}{l}\text { Hevels } / \text { resource } \\
\text { consumption }\end{array}$ & Livestock stocking rates & Affects GHG emissions \\
\hline $\begin{array}{l}\text { Climate variability } \\
\text { and change }\end{array}$ & $\begin{array}{l}\text { Temperature and precipitation } \\
\mathrm{CO}_{2} \text { and ocean acidification }\end{array}$ & $\begin{array}{l}\text { Affects existing carbon stores, evapotranspiration } \\
\text { Affects existing carbon stores, GHG emissions, and } \\
\text { aerosol sources }\end{array}$ \\
\hline
\end{tabular}

of provisioning services [7]. The regulating services provided by ecosystems are diverse, among which climate regulation is a final ecosystem service. The ecosystems regulate climate through biogeochemical and biogeophysical processes [6], as sources or sinks of greenhouse gases (GHGs) and as sources of aerosols all of which affect temperature and cloud formation [10-13].

The processes involved in climate regulation include the following: (1) through the $\mathrm{CO}_{2}$ in the atmosphere was absorbed photosynthesis; (2) evapotranspiration from soils and plants controls the amount of water vapour entering the atmosphere, thus regulating cloud formation and the radiative properties of the atmosphere; (3) the change of the albedo of different land surfaces can affect the climate; for example, the change in vegetation can have a cooling or heating effect on the surface climate and may affect precipitation; (4) the regulation of aerosols comes from soil erosion or vegetation through vegetation scavenging, which affects radiative heating of the atmosphere, surface albedo, and so forth [12].

There are many direct and indirect drivers that can affect the process of climate regulation services. For the systematic understanding of the effect mechanism and quantitative evaluation of the effects on climate regulation, it is important to clarify the major drivers and quantitatively analyze the effects induced by LUC and climate changes on those drivers through both biogeochemical and biophysical process. Comparatively, a direct driver more unequivocally influences ecosystem processes, while an indirect driver operates more diffusely by altering one or more direct drivers; that is, direct drivers have much more explicit effects on ecosystem processes [14] and usually cause physical change that can be identified and monitored [15]. As to climate regulation services, the indirect drivers mainly include demographic drivers (population growth and distribution, migration and ethnicity, etc.), economic drivers (economic growth and consumer choice, market force, industry size and globalization, etc.), and sociopolitical drivers (legislation, regulation, etc.) [16].
The direct drivers are listed in Table 1, among which land use drivers are the most important in the ecosystem context and can be identified as the main drivers of climate regulation [17], while over longer term, climate changes will also have feedback to climate regulation services [18].

In this study, we focus on choosing close researches to explore how LUC and climate changes affect the climate regulation through biogeochemical and biogeophysical processes, respectively. Then incorporating with the effects on climate regulation services and researches on impact assessment for human well-being were further revisited. This study, firstly describes the climate regulation services and the needs and significance to study climate regulation services, then examines how LUC and climate changes affect climate regulation services through review of the researches on major drivers, and after that outlines how changes of the role of ecosystem services in regulating climate affect human wellbeing through investigation of four major aspects (economic value, extreme weather, food security, and human health) that are closely related with human well-being. This review study intends to provide a reference for the future research on LUC, climate changes, climate regulation services, and human wellbeing. The framework for the review about the effects induced by LUC and climate changes on climate regulation and further impact assessment for human well-being is shown in Figure 1.

\section{Research on LUC Induced Effects on Climate Regulation Services}

As mentioned above, LUC plays an important role in climate regulation. Anthropogenic land use has been and will continue to be a major driver of the changes in climate system [17]. And there have been many observations and simulations revealing that LUC exerts effects on climate regulation services through biogeochemical and biogeophysical processes. 


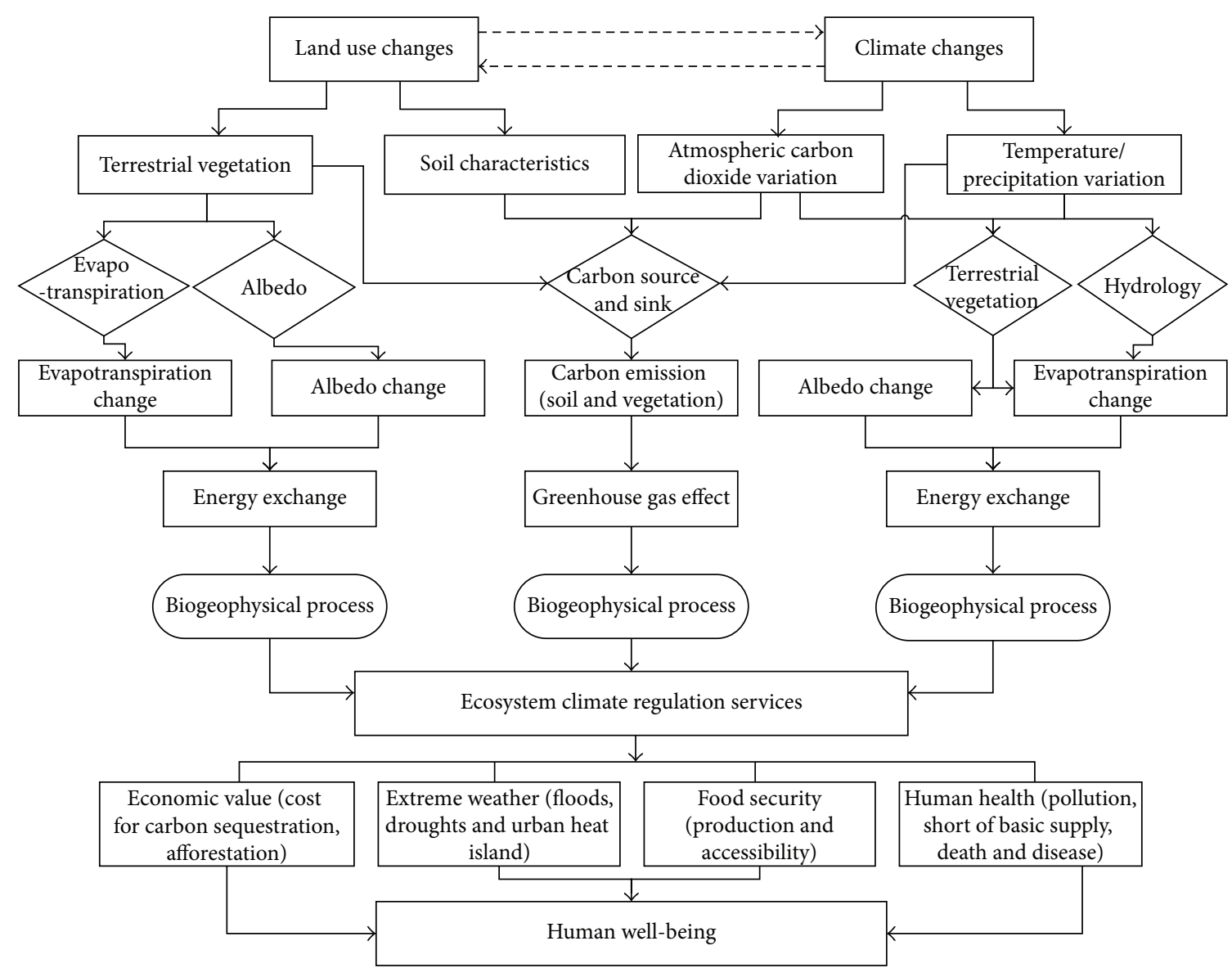

FIGURE 1: Framework for integrating land-use induced effects on climate regulation services into impact assessment for human well-being.

2.1. Consideration of the Cumulative Effects through Biogeochemical Processes. In terms of biogeochemical processes, LUC mainly affects the climate regulation services through the emission and sequestration of GHGs, especially through altering $\mathrm{CO}_{2}$ flux. The total amount of carbon stored in terrestrial biosphere is an important factor in climate regulation [19]. Terrestrial ecosystems contribute to climate regulation primarily through carbon dynamics. Plants absorb $\mathrm{CO}_{2}$ through photosynthesis, storing carbon in vegetation and soils, and the carbon accumulated in soil and biomass represents a pool of carbon which is greater than the atmospheric carbon pool [20]. Deforestation, forest degradation, and other land use practices accounted for approximately $20 \%$ of global anthropogenic $\mathrm{CO}_{2}$ emissions during the 1990s [21]. When carbon is released from the earth during cultivation, deforestation, fire, and other land use practices, it binds with other chemicals to form GHGs in the atmosphere and accelerates global climate changes $[21,22]$. The conservation of carbon sinks or pools is therefore important to mitigate GHGs levels. Thus it is of great significance to investigate the effect of LUC on climate regulation through its biogeochemical process, that is, through the effects on the cycle of carbon. And LUC can change the release of carbon to the atmosphere mainly through the disturbance on terrestrial vegetation and soils [23].
2.1.1. Biogeochemical Process Related with Terrestrial Vegetation. Terrestrial vegetation is a large carbon sink which plays an important role in the global carbon cycle and is valued globally for the services it provides to society. Vegetation classifications have been related to climate variables and used in assessment of possible global response to climate changes [24-26]. Olson et al. (1983) built up a computerized data base to document the map of vegetation and corresponding carbon density for natural and modified complexes of ecosystems. The map provides a basis for making improved estimates of vegetation areas and carbon quantities [27], illustrating that different types of vegetation have various ability of carbon sequestration. LUC can have great effects on the structure of terrestrial vegetation [28]; for example, once the forest is being converted to cultivated land, the biodiversity will decline. The distribution of sources and sinks of carbon among the world's terrestrial ecosystem is uncertain, through deforestation, urbanization, expansion of cultivated land, and other land use practices; LUC variously alter the land surface and species compositions and exert various effects on the carbon cycle.

It is relatively difficult to quantify the process that LUC affect the carbon sink or net source of terrestrial vegetation. Most researches developed and applied different models to record the carbon emission or sequestration resulted from 
LUC. Firstly, many researchers adopted empirical data to simulate carbon emission and sequestration. Houghton et al. $(1983,1999,2000$, and 2003) calculated the carbon emission resulting from LUC and the potential for sequestering carbon of different land covers mainly based on the parameters set for each vegetation type in each regime [29-36], and the model was called the "bookkeeping" terrestrial carbon model. Further, Houghton et al. (2001) documented a numeric data package that consists of annual estimates of the net flux of carbon between terrestrial ecosystems and the atmosphere resulting from deliberate LUC, especially forest clearing for agriculture and the harvest of wood for wood products or energy from 1850 through 1990 [37]. DeFries et al. (2002) further apply the "bookkeeping" model in conjunction with multiple sources of remote-sensing data to estimate carbon fluxes from tropical LUC [38]. The "bookkeeping" model tracks the amount of carbon released to the atmosphere from clearing and decay of plant material and pluses the amount of carbon accumulated as vegetation grows back. However, the parameters in the "bookkeeping" model are mainly based on empirical data and lack mechanism process. Then some researches started to combine process-based ecosystem models with the "bookkeeping" model, which can associate the land use information with its related process and thus enhanced the accuracy of the estimation. For example, one type of the process-based ecosystem model, the Terrestrial Ecosystem Model (TEM), in which the effect of LUC was characterized by the specific parameters of the function of different vegetation types, can be combined with the "bookkeeping" [19]. And DeFries et al. (1999) predicted the effect of LUC on carbon cycle based on the vegetation distribution information derived from remote sensing data and combined with Carnegie-Ames-Stanford Approach Model (CASA) [39]. What is more, Sitch et al. (2003) also coupled the "bookkeeping" model with Lund-Potsdam-Jean dynamic global vegetation model (LPJ) [40]. Particularly, McGuire et al. (2001) combined four models, that is, TEM, High Resolution Biosphere Model (HRBM), LPJ, and Integrated Biosphere Simulator (IBIS) model [19]. And Levy et al. (2004) combine the HYBRID vegetation dynamic model with the "bookkeeping" model to estimate the carbon dynamic resulted from LUC [41]. Differently, Schröter et al. (2005) used a range of ecosystem models and scenarios of climate and LUC to assess the vulnerability of ecosystem services, and the simulation results showed that LUC affected terrestrial carbon sink positively through decreases in agricultural land and increased afforestation during the 21th century [1]. Different models have different results about the amount of the carbon emission induced by LUC, but all the results show that global deforestation can lead to large carbon emission.

Among all the vegetation types, forest as one of the productive area is a major part of terrestrial ecosystem. Global deforestation has great effect on the carbon emission [42]. Using forest inventory data and long-term ecosystem carbon studies, Pan et al. (2011) estimated a total forest sink of $2.4 \pm 0.4$ petagrams of carbon per year $\left(\mathrm{Pg} \mathrm{C}_{\mathrm{Cear}}{ }^{-1}\right)$ globally for 1990-2007, and tropical deforestation around the world contributes to a gross emission of $2.9 \pm 0.5 \mathrm{Pg} \mathrm{C}$ year $^{-1}$, which was equal to $40 \%$ of global fossil fuel emissions [43].
Combined with spatial explicit information on changes in forest area which derived from satellite observations and terrestrial carbon models, many researches focused on the tropics to detect whether tropic deforestation act as carbon sink or net source and identified that tropics acted as carbon sink [38, 44]. Explicitly, Arora et al. (2009) assessed the biogeochemical behavior of the CCCma earth system model (CanESM1) against observations for 1850-2000 and then compared simulated atmospheric $\mathrm{CO}_{2}$ concentration with available observations and observation-based estimates; the simulation results showed that forests' different photosynthesis ability and $\mathrm{CO}_{2}$ emissions from LUC resulted in different density of $\mathrm{CO}_{2}$ in atmosphere, which indicated that the tropics were large carbon sinks [45].

Currently, based on model simulation, it was acknowledged that LUC can affect the carbon sink or source. Firstly, many researches were based on empirical data and statistical models which can use only observation data about the land cover without knowing conversions among different land cover types. While with the application of remote sensing and developed ecosystem models, the carbon emission induced by LUC can be more accurately estimated. However, most models also cannot take some important factors into account, such as the feedback of regional climate change, the water cycle before and after LUC, and the physical structure of soil. More efforts should be devoted to develop models that can comprehensively integrate all the factors to do simulations.

2.1.2. Biogeochemical Process Related with Soil Carbon. The changes of LUC can affect the sink of carbon not only through the sequestration of vegetation covering the land, but also through the changes of soil characteristic of different land cover types. It has been identified that different land cover types' potentials of soil carbon are various. For example, tropical forests were estimated to store approximately $206 \mathrm{Pg}$ $C$ in the soil globally [4], which was relatively less than half of that of boreal forests' soil [18, 46]. And explicitly, wet and moist tropical forests tend to have greater soil carbon pools per unit area than tropical dry forests due to higher rates of Net Primary Productivity (NPP) [47]. The potential of cropland soils [48] and grazing land soils [49] to sequester carbon and mitigate the greenhouse effect are different. Dawson and Smith (2009) reviewed effects of LUC and climate changes on soil carbon losses and found that the soil carbon emissions of agriculture land (cropland and grassland), forestry land, and peatlands/wetlands explicitly have different ability of carbon sequestration, and human's land use management is critical to regulate carbon emission [50].

LUC plays an important role in determining whether soil is a sink or source of atmospheric $\mathrm{CO}_{2}$, since it can change the amount of soil carbon sequestration. For example, deforestation can result in an initial loss of carbon from soils due to increased decomposition rates, erosion, and reduced inputs of vegetation residues, namely, soil organic matters (SOM) [51]. Ayanaba et al. (1976) reported that deforestation for cultivated land leads to the reduction of soil total carbon content [52]. As most researches about the effect of deforestation on soil carbon only focused on one kind of land conversion while did not simultaneously take all 
the land cover types into consideration, Powers (2004) presented better understanding of the effects of LUC on regional and global ecosystem process by considering all of the land use conversions that occur in the landscape and detect the difference among the effects on soil carbon of each land use conversion based on statistical analyze [53]. Scott et al. (2002) designed a soil carbon monitoring system for New Zealand using country-specific land use and soil carbon information, which can be used to estimate both soil carbon stocks at a single point in time and also future soil carbon stocks in response to LUC [54].

LUC affect the soil carbon content mainly through regulating soil organic carbon (SOC) pools [55]. The dynamic changes of SOC have a strong effect on atmospheric composition and the rate of climate change, thus playing an important role in climate regulation. There have been many studies quantifying the effects of LUC on SOC, and since the carbon dynamics in soil are a long-term process which is relatively difficult for doing field researches and observations, most of the studies were based on model simulations. The major SOM models include SOM model (SOMM), Institute of Terrestrial Ecology-Edinburg (ITE), Verberne, Rothamsted C model (ROTHC), Carbon-Nitrogen-Dynamics (CANDY), DeNitrification and DeComposition (DNDC), CENTURY, DAISY, and NCSOIL, and so forth. Smith et al. (1997) compared these nine models with data from seven long-term experiments representing multiple vegetation and management conditions [56]; the results showed that a comparison of the overall performance of models across all datasets reveals that the model errors of one group of models (ROTHC, CANDY, DNDC, CENTURY, DAISY, and NCSOIL) did not differ significantly from each other. Another group (SOMM, ITE, and Verberne) did not differ significantly from each other but showed significantly larger model errors than did models in the first group. Among all the nine models, ROTHC and CENTURY are two of the most widely used and tested SOM models. Shrestha et al. (2009) used the Century model to simulate changes in SOC pool over 100 years (1950-2050) under managed dense Shorea forest, rainfed upland, and irrigated low land in a midhill watershed of Nepal [57]. And Dieye et al. (2012) analyzed the sensitivity of the GEMS soil organic carbon model in response to LUC [58]; the GEMS model was also developed from the CENTURY model [59]. Barancikova et al. (2010) and Francaviglia et al. (2012) used the ROTHC model to simulate the changes in agricultural land's SOC pools $[60,61]$. SOC cannot only be affected by LUC, but also by climate change, which will be revisited in Section 3.1.

\subsubsection{Combined Biogeochemical Process of Terrestrial Vegeta-} tion and Soil. As mentioned above, most researches focused on the calculation of carbon emission resulted from the terrestrial vegetation changes with different models and methodologies, based on the historical observations or scenarios analysis. And also there are researches trying to figure out the change of carbon emission as the change of soil characteristic of different land cover types resulted from land use management practices. However, it is also important to combine the two biogeochemical processes together to detect the effect of LUC on carbon cycle and further analyze the effect on climate regulation services.

As to this point of view, Woomer et al. (2004) defined the total carbon in the ecosystem as the sum of the woody biomass, herbaceous biomass, root, litter, and soil carbon pools, and using an inventory procedure involving satellite images which reveal historical LUC and recent field measurements of standing carbon stocks occurring in soil and plant; they estimated Senegal's terrestrial carbon stocks in 1965,1985 , and 2000 [62]. In addition, the changes of carbon emission from vegetation and soil resulted from LUC and climate changes can also counteract with each other. Synthetically considering the carbon emission from vegetation and soil induced by LUC and climate changes, based on a series of ecosystem models and scenarios of LUC and climate changes to evaluate the ecosystem service supply and vulnerability, Schröter et al. (2005) confirmed that Europe's terrestrial biosphere acted as a net carbon sink, with decreased agricultural land and increased afforestation resulting in the increasing sequestrated amount of carbon, while soil carbon losses due to warming would balance the carbon sequestrated by terrestrial biosphere by 2050 and lead to carbon releases by the end of this century [1]. In the Integrated Valuation of Ecosystem Services and Tradeoffs (InVEST) model, a simplified carbon cycle that maps and quantifies the amount of stored and sequestered carbon based on five carbon pools (above ground biomass, below ground biomass, soil, dead organic matter, and harvested wood products) is incorporated [63]. Leh et al. (2013) used average literature values in the InVest model to calculate the carbon as part of the ecosystem services in major land classes according to the proportion of land use land cover (LULC) area in Ghana and Cote d'Ivoire, West Africa [64]; the model is of great significance to evaluate the ecosystem services.

In summary, effect on climate regulation through biogeochemical process mainly focuses on the carbon emission and sequestration both in terrestrial vegetation and soil; from comprehensive and global perspective, it is important to regulate the carbon cycle to control global warming and there should be more researches to combine the whole biogeochemical processes of LUC's effect on carbon cycle together to provide references for decision-makers to make land use management practices.

\subsection{Overall Effects Accounting through Biogeophysical Pro-} cesses. LUC is a general term for the human modification of Earth's terrestrial surface, and the albedo and evapotranspiration of different surfaces vary with land cover types. The biogeophysical effect mechanisms of LUC on climate regulation are mainly through changing the albedo and evapotranspiration, which are closely related with energy flux between land surface and atmosphere $[23,65-70]$.

2.2.1. Biogeophysical Process Related with Albedo. Albedo represents the fraction of incoming radiation reflected by the surface. A reduction in albedo means that a larger fraction of the incoming radiative energy is absorbed by the surface, further results in warming [71]. The effect of albedo changes on regional and local climates is a research hotspot, 
especially changes in climate in response to changes of vegetated land cover and built-up areas. These changes alter surface heat balance not only by changing surface albedo, but also by altering evaporative heat transfer caused by evapotranspiration from vegetation and by changes in surface roughness [23].

Land surface with different vegetation types possesses different albedos; for example, forests typically have lower albedos than bare ground, grassland, and cropland; therefore, absorb more incoming solar radiation [12, 17], indicating that different vegetation types participated in the land surface play a role in regulating surface energy, thus affecting surface climate. Based on different methodologies and models, there have been many researches focusing on the net radiation associated with the change of albedo resulted from LUC. In the 1970s, Charney (1975) firstly pointed out that albedo changes play an important role in global climate based on Global Climate Model (GCM) and put forward the biogeophysical feedback mechanism [72]. The mechanism explains that vegetation reduction due to drought will lead to increasing the albedo, decreasing the net radiation of the surface and corresponding sensible and latent heat, and further weakening the convergence upward movement, thus resulting in the reduction of cloud and precipitation. It can be seen that albedo plays an important role in surface net radiation and energy exchange. The radiative forcing due to surface albedo change can be simulated with the radiative transfer scheme of the third Hadley Centre Atmosphere Model (HadAM3) [73]. Betts (2000) applied HadAM3 to simulate the radiative forcing associated with changes in surface albedo and revealed that decreasing albedo exerts a positive radiative forcing on climate [65]. Snyder et al. (2004) investigated the participation of different vegetation types within the physical climate system based on CCM3-IBIS (the Community Climate Model coupled to the Integrated BIosphere Simulator), a coupled atmosphere-biosphere model, analyzed the effects of six different vegetation biomes (tropical, boreal, and temperate forests, savanna, grassland and steppe, and shrubland/tundra) on the climate through their role in modulating the biogeophysical exchanges of energy, water, and momentum between the land-surface and the atmosphere, and explained the role of the albedo in modifying the surface radiation budget [70].

\subsubsection{Biogeophysical Process Related with Evapotranspiration.} Evapotranspiration causes local cooling due to latent heat transfer from the surface to the atmosphere. Evapotranspiration can also influence cloud cover, which, in turn, affects the amount of energy reaching the surface [71]. Clearing vegetation reduces evapotranspiration and associated latent heat flux, as without the vegetation, energy normally used to evaporate water instead of heating the land [17]. Evapotranspiration is an important ecosystem integrity indicator and is strongly related to land cover types. The process of evapotranspiration consumes energy and therefore has a cooling effect and a positive effect on microclimate regulation. To quantify the climate regulation and assess the effect of LUC on climate regulation, Kroll et al. (2009) used thermal emissions of different land use classes with different land surface emissivity derived from remote sensing data and land cover information of MOLAND classification based on PLUREL scenario [74]. And Twine et al. (2004) analyzed the effects of LUC on the energy and water balance of the Mississippi River basin using the IBIS model, in which the forest cover was assumed to be completely converted to crop cover which resulted in decreasing annual average net radiation and evapotranspiration [75]. In order to assess the effect of LUC on evapotranspiration, Liu et al. (2008) used Dynamic Land Ecosystem Model (DLEM) in conjunction with spatial data of LUC to estimate the LUC's effects on the magnitude, spatial and temporal variations of evapotranspiration in China, and results showed that deforestation averagely increased evapotranspiration by $138 \mathrm{~mm} /$ year and urban sprawl generally decreased evapotranspiration $98 \mathrm{~mm} /$ year during $1900-2000$, and so forth [76]. Yang et al. (2012) first used a knowledge-based decision tree (K-DT) classification technique to detect LUC which was characterized with deforestation and expansion of farmland, barren land and residential land, then a two-source potential evapotranspiration (PET) model was used to estimate the potential evapotranspiration response to LUC, and the result showed a decreasing trend of PET at Shalamulun River watershed in China [77]. And more efforts on quantifying the biogeophysical regulation of climate by ecosystems have largely focused on regional analyses, using GCMs that include landsurface models coupled with atmospheric circulation models, and these regional-scale analyses have focused on areas with strong land-climate feedbacks, including the Amazon $[66,78]$ and boreal regions [79].

As mentioned above, current approaches for quantifying the biogeophysical regulation of climate by ecosystems (especially through effects on atmospheric heat and moisture) were mainly concentrated on highly complex models, especially atmospheric models, such as HadAM3 and GCMs; thus few nonmeteorologists have access (or the expertise) to run and interpret high complex systems; then West et al. (2010) put forward an alternative approach for quantifying climate regulation by ecosystem; they developed a simple climate regulation index that could quickly produce approximations of biogeophysical regulation of climate by terrestrial ecosystems, in which the potential effects of LUC on biogeophysical climate regulation were estimated based on comparing a natural vegetation scenario to a bare ground scenario [69]. However, conversion of natural land to other land-cover types can have different results; thus the model has potential to be improved.

In some sense, researches of effect on climate regulation of LUC through biogeophysical process are of great significance and mainly focused on the net radiation, energy balance and so forth, which is related with albedo change and evapotranspiration rate. And most researchers simulate the effects with complex atmospheric models, biosphere models, and combined models, and the effect mechanism is relatively similar, while more attention should be paid to how to integrate and simplify the whole process to support most policymakers, nonmeteorologists, and other related people decision making. 


\section{Identification on the Effects on Climate Regulation Services due to Climate Changes}

According to the forth report of Intergovernmental Panel on Climate change (IPCC AR4, 2007), there is more than $90 \%$ probability that human activities have affected the climate [21], mainly through two approaches: fossil fuel burning and land use/cover change. LUC cannot only directly exert effect on the drivers of climate regulation, but also indirectly through its impact on climate changes [80-82]. And climate changes (temperature and precipitation variation and $\mathrm{CO}_{2}$ variation) are also likely to put many ecosystem services that humans derive from lands, waters, and so forth at risk. Over the long term, climate changes will feed back to climate regulation services [1] also through both biogeochemical and biogeophysical process.

3.1. Biogeochemical Process of the Effect on Climate Regulation Services. The amount of carbon in atmosphere is important to climate regulation services. Climate variations, such as the changes of temperature, precipitation, and atmospheric $\mathrm{CO}_{2}$ content affect existing carbon stores through biogeochemical process. Friedlingstein et al. (2006) used eleven coupled climate-carbon cycle models with a common protocol to study the coupling between climate changes and the carbon cycle, through the feedback analysis; their results indicated that future climate changes will reduce the efficiency of the earth system to absorb the anthropogenic carbon perturbation [83]. And as to carbon accumulation, soil carbon is a major component of global carbon inventory which interact with atmospheric $\mathrm{CO}_{2}$. Rising atmospheric $\mathrm{CO}_{2}$ concentrations will increase radiative forcing and is expected to increase soil temperatures and accelerate decomposition rates of SOC, which, in return, will increase $\mathrm{CO}_{2}$ accumulation rate in the atmosphere [84-86].

Regarding the temperature changes, which are major elements affecting the photosynthesis [87] and decomposition of SOM [88]. Jenkinson et al. (1991) used the Rothamsted model for the turnover of organic matter in soil to calculate the amount of $\mathrm{CO}_{2}$ that would be released from the world stock of SOM if temperatures increase as predicted and the annual return of plant debris to the soil being held constant. The results showed that if world temperatures rise by $0.03^{\circ} \mathrm{C}$ per year, the additional release of $\mathrm{CO}_{2}$ from $\mathrm{SOM}$ over the next 60 years will be $61 \times 10^{15} \mathrm{gC}$ [89]. The temperature's effect on soil carbon losses is also confirmed by recent experimental and modeling studies [90-93] and lots of experimental studies overwhelmingly indicate that increased SOC decomposition resulting from higher temperature led to increased $\mathrm{CO}_{2}$ emissions from soils [91, 94, 95]. In addition to carbon emission, soil carbon sequestration can be regulated by temperature change $[93,96]$.

As to moisture or precipitation conditions, in mature tropical forests, soil carbon pools tend to decrease exponentially as the ratio of temperature to precipitation increases, corresponding to a gradient from wet to dry forests [47]. Albani et al. (2006) used ecosystem demography (ED) model, through comparison between the patterns of variability in net ecosystem productivity (NEP) with the patterns of temperature and precipitation variability from 1948 to 2003 and revealed that the periods of carbon losses during the 1960s were caused by anomalously dry conditions, while the carbon losses that occurred in the late 1990s were due to a combination of reduced precipitation and anomalously warm temperatures in the Eastern US [97]. What is more, to better quantify climate changes' effect on soil carbon, Ise and Moorcroft (2006) used a mechanistic decomposition model in which the effects of temperature and moisture are multiplicative, to estimate the global-scale temperature and moisture dependencies of SOC decomposition, the results indicated that modeling of temperature and moisture dependencies of SOC decomposition in global-scale models should consider effects of scale which were not considered in other models [88]. And as mentioned in Section 2.1.3, SOC can also be affected by climate change. In many SOM models, climate data are important part as the input data into the models, and SOC changes in response to climate changes under different climate scenarios which derived from GCMs and other climate models were usually analyzed $[60,61,98]$. What is more, as the biogeochemical process of carbon sequestration is complex, it is difficult to take into account of all influencing factors; Zhan et al. (2012) used a panel data model and decomposition analyses to figure out the subtle effects of climatic, demographic, geographic, and economic factors, which revealed the importance of climatic factors in carbon sequestration [99].

\subsection{Biogeophysical Process of the Effects on Climate Regu-} lation. Human induced climate changes are also important factors affecting the climate regulation services. Along with the industrialization and other human activities, the global climate showed a warming trend, which in the long-term will return feedback to climate regulation services through biogeophysical process.

3.2.1. Effect on Evapotranspiration. Climate changes can exert effects on the hydrological cycle and alter the evapotranspiration that both with implication for ecosystem services and feedback to regional and global climate. Land evapotranspiration is a central process in the climate system and a nexus of the water, energy, and carbon cycles [100]. As evapotranspiration cannot be measured directly at the scale of climate observations and climate predictions, therefore most researches generally applied hydrological models to estimate the effect of climate changes on evapotranspiration [101]; among the models, different PET models are often used. To accurately detect the effect of climate changes on PET, more and more researchers turned over to analyze the sensitivity of these models to climate changes [102-105].

\subsubsection{Effect on Albedo due to Changes of Terrestrial Vegetation.} Climate changes can also exert effect on climate regulation via the change of vegetation which plays an important role in climate regulation through albedo and evapotranspiration change. The response of terrestrial vegetation to climate changes has long been a research hotspot; there are many studies about understanding and quantifying climateinduced vegetation change $[106,107]$. 
Regarding temperature and precipitation changes, Overpeck et al. (1990) used the FORENA model to simulate the effects of climate changes on four forest types in eastern North America with three types of climate change experiments; the results indicated that climate changes would induce increases in forest and vegetation disturbance, which can significantly alter the total biomass and compositional response of forests to future warming [108]. As anthropogenic increases in the atmospheric concentration of $\mathrm{CO}_{2}$ and other GHGs are predicted to cause a warming of the global climate by modifying radiative forcing [109], Peters and Darling (1985) had a widespread hypothesis that global warming resulted from greenhouse effect can diminish biological diversity and shift the terrestrial pattern [110]. Moreover, corresponding climate changes with enriched $\mathrm{CO}_{2}$ may also alter the density of vegetation cover, thus modifying the physical characteristics of the land surface to provide climate feedback. In a vegetation/ecosystem modeling and analysis project (1995), three biogeochemical models (BIOME-BGC (BioGeochemistry Cycles), CENTURY, and TEM) and three biogeophysical models (BIOME2, Dynamic Global Phytogeography Model (DOLY), and Mapped Atmosphere-Plant Soil System (MAPSS)) were applied, respectively, to simulate the geographic distribution of vegetation types under doubled $\mathrm{CO}_{2}$ and a range of climate scenarios (temperature and precipitation variations), and the results indicated that carbon concentration and temperature and precipitation variations can obviously change the distribution of vegetation types [111]. Betts et al. (1997) used a general circulation model iteratively coupled with an equilibrium vegetation model to quantify the effects of both physiological and structural vegetation feedbacks on a doubled- $\mathrm{CO}_{2}$ climate, with the output vegetation structure mainly represented by Leaf Area Index (LAI). The results showed that changes in vegetation structure can significantly feed back to regional-scale climate [112]. The vegetation structure feeds back to climate mainly through two opposite effects; increased LAI tended to warm the land surface by lowering its albedo and cool the land surface by enhancing evaporation, while decreased LAI tended to cool the surface via increased albedo and warm the surface via reduced evaporation $[79,113]$. To understand how vegetation growth responded to the climatic variations, Piao et al. (2006) took the LAI as an indicator to represent the vegetation activity and based on a mechanism terrestrial carbon model, to detect effect of current climate changes on vegetation growth in the northern hemisphere, and results showed that the vegetation change in different areas can be explained by temperature and precipitation, respectively [114].

Most of the researches focused on terrestrial vegetation ecosystem, while Lovelock and Kump (1994) suggested that if living organism participates in climate regulation in an active and responsive way, they do most probably as part of a tightly coupled system, which includes the biota, the atmosphere, the ocean, and the crustal rock. Within such system, the growth of organisms changes environmental conditions and environmental changes feed back to the growth. Thus they conducted qualitative analysis of the effects of temperature change on the feedbacks induced by changes in surface distribution of both marine algae and land plants, as to detect how the planetary area occupied by these two ecosystems varies with temperature [115]. There are many kinds of ecosystems on the earth, among which terrestrial ecosystem is much more connected with human beings, while it is also of great significance to do researches that combine other ecosystems with terrestrial ecosystem to comprehensively detect the impact mechanism of LUC and climate changes.

\section{Impact Assessment for Human Well-Being due to Land-Use Induced Climate Regulation Services Changes}

According to the Millennium Ecosystem Assessment (2005), human well-being is assumed to have multiple constituents, including the basic material for a good life (adequate livelihoods, sufficient nutrient food, shelters, access to goods, etc.); health (feeling well, access to clean air and water, etc.); security (secure resource access, personal safety, and security from disasters, etc.), and freedom of choice and action and so forth [6]. The services provided by ecosystems for all those unalterable needs indicate that ecosystem services are essential to human well-being. Climate regulation relates to the maintenance of a favorable climate, both at local and global scales, which has important implications for health, crop productivity, and other human activities [7]. In this paper, we reviewed how changes in the role of ecosystem services in regulating climate affect human well-being, mainly including economy benefits, food security, human health, and a healthy environment.

\subsection{Economic Value Determined by Climate Regulation.} Ecosystem services and the natural capital stocks that produce the services are critical to support the earth's life system, contribute to human well-being both directly and indirectly, and therefore represent part of the total economic value of the planet. Costanza et al. (1997) firstly developed the Ecosystem Value System (ESV) calculation system to estimate the economic value of 17 ecosystem services (including climate regulation services) for 16 biomes, in which land use is one of the major factors [116]. Based on the ESV calculation system, some researchers examine the potential effects of the past and future LUC on the ecosystem services $[117,118]$, and the results showed that the changes of ecosystem services value (among which climate regulation accounted for $10 \%$ of the change) in Baguio city about $98 \%$ were due to forest cover loss for 1988-2009.

Forest ecosystems play an important role in climate regulation through trapping moisture and cooling the earth's surface, thus regulating precipitation and temperature. Costanza et al. (1997) found that forests yield US $\$ 450$ per hectare per year in terms of climate regulation benefits [116]. Explicitly, in the urban context which is directly related with human well-being, urban and community forests can strongly influence the physical/biological environment and mitigate many effects of urban development by moderating climate, conserving energy, $\mathrm{CO}_{2}$, and water, improving air quality, controlling rainfall runoff, and so forth. As in the case of Tucson, Arizona, each tree would give benefits in the range 
of US $\$ 20.75$ annually by reducing cooling costs for buildings [119]. Dwyer et al. (1992) calculated that 100 million mature trees in US cities could reduce annual energy costs by US $\$ 2$ billion based on computer simulations estimate [120].

LUC and climate changes can exert effect on the capacity of ecosystem to absorb carbon, which will result in the loss of climate regulation services and further loss of socioeconomic benefits. To estimate the value of carbon sequestration in Uganda's protected area, Howard (1995) used two different approaches: first, based on figures of the damage that would occur if the land was converted and carbon released in the atmosphere, the value of Uganda's protected areas as a carbon sink was estimated at US $\$ 245$ million, which amounts to a US\$17.4 million annually; second, the replacement cost approach was also used to estimate the cost of replacing this carbon sink functions through an afforestation scheme and was valued at US $\$ 20.3$ million annually [121]. The results indicated that along with the degradation or loss of climate regulation services in carbon sequestration, much cost will be input to ecological engineering, such as afforestation and construction of environmental protection area.

4.2. Effects of Extreme Weather Events. In response to ecosystem services changes, extreme weather events directly affect human well-beings, leading to drastic disasters which can influence most aspects of humans, such as living environment, agriculture production, and health. Regional climatic conditions are influenced by changes in ecosystems and landscapes, especially deforestation and desertification. Human-induced alteration of atmospheric composition (the greenhouse effect) also affects climatic conditions. On a large scale, the long-term ongoing GHGs effect will lead to increasing risks of deaths in extreme weather events (heat waves, floods, droughts, etc.) [122]. These events have local and sometimes regional effects, directly through deaths and injuries and indirectly through economic disruption, infrastructure damage, and population displacement. In turn, this may lead to increased incidence of certain communicable diseases as a result of overcrowding, lack of clean water and shelter, poor nutritional status, and adverse effects on mental health.

Climate regulation of hydrology is a research area, in which natural climate system affect hydrology and further exert effect on the runoff, rainfall cyclicity, water quality, soil development, and so forth $[123,124]$. As a result, there are marked variations in the likelihood of flooding and droughts, the intensity of erosion and nutrient cycling, and the demand for irrigation water and water supplies, which further will bring substantial loss of human well-being. And as to urban ecosystem, climate changes caused by increased anthropogenic emissions of $\mathrm{CO}_{2}$ and other GHGs are a longterm climate hazard with the potential to alter the intensity, temporal pattern, and spatial extent of the urban heat island in metropolitan regions [125]. The microclimate regulation of all natural ecosystem in the urban areas contribute to reducing the urban heat island effect, as urban green increases evapotranspiration and therefore has a cooling effect; from the perspective of economics, vegetation can also decrease energy use for heating and air conditioning substantially in urban areas by shading house in summer and reducing wind speed in winter [126].

4.3. Response of Food Security to Climate Regulation. The accessibility of food is highly dependent on suitable climatic conditions, and the sustainable production of food and raw materials is vulnerable to changes in temperature, precipitation, and concentrations of $\mathrm{CO}_{2}$. Though the role of climate regulation in food security has not been fully estimated [127], the climate variability which can result from LUC, has been examined as the principal source of fluctuations in global food production in different areas, such as the arid and semiarid tropical countries of the developing world, the northern China, and so forth [128-130]. Specifically speaking, soil carbon sequestration can be regulated by climate changes, especially the changes result from temperature change [93, 96] and LUC. As land is the basic requirement for cultivation of crops, a region's potential for food production in agricultural areas depends directly on the fertility of available arable lands [131], and soil carbon sequestration is a key element for ecosystem biogeochemical carbon cycle and contributes to the formation of fertility in soil, which helps to maintain net productivity, improve water quality, and restore degraded soils and ecosystems $[20,132]$. Thus along with the climate regulation services changes, the variability of soil carbon sequestration results in the change of food production and accessibility.

4.4. Consequence on Human Health. In the Millennium Ecosystem Assessment, it was stated that stresses on freshwater sources, food-producing systems, and climate regulation could cause major adverse health effects, and each ecosystem service is sensitive to climate conditions which will be affected by LUC and climate changes. And the change of ecosystem services will affect the human well-being and health of human [122]. Climate regulation is one of the services the ecosystems provide to regulate climate conditions, mainly to ensure that people live an environmentally clean and safe life [133]. The degradation of climate regulation will decrease the ability of ecosystem to avoid the adverse effect of climate changes and can affect human health through both direct effect (such as increasing mortality, diseases from extreme weather) and indirect effects (such as climate-induced changes in the distribution of productive ecosystems and the availability of food, water, and energy supplies). Although climate changes may have some benefits to human health, most are expected to be negative especially in urban areas. As human migrate from rural areas to cities, more than half of the world's population now live in high-density urban areas, many of which are poorly supplied with either ecosystem or human services [122]. And in these urban areas, a reduction in climate regulation services could exacerbate climate stress for large numbers of people, reducing well-being and increasing death rates directly through higher summer temperatures and so forth [16]. Furthermore, climate regulation services of soil carbon sequestration can help mitigate climate changes by offsetting emissions of fossil fuels and reducing GHGs effects, and so forth, which is of great significance to improve environment for healthy lives $[132,134]$. 


\section{Concluding Remarks}

LUC and climate changes will alter the supply of ecosystem services that are vital for human well-being. The processes through LUC and climate changes influence human wellbeing via exerting effects on climate regulation services are complex and complicated, involving both biogeochemical and biogeophysical processes. From the perspective of the drivers of and their corresponding effects on climate regulation services, this paper mainly revisited the closely related researches to explore how LUC and climate changes exert effects on the major drivers, such as carbon emission and sequestration, albedo, and evapotranspiration which are key elements to regulate surface energy exchange and further play an important role in climate regulation services. And, along with the changes of climate regulation services resulted from LUC and climate change, different aspects of human well-beings will be impacted which have also been assessed by many researchers. Generally speaking, LUC and climate changes have great effects on climate regulation services. Globally, deforestation, degradation of forest and grassland, land conversion from forest to cultivated land, urban expansion, carbon emission, and so forth all will probably lead to changes in climate regulation services.

So far, lots of researches have been conducted and significant progresses have been made related to each aspect shown in Figure 1. However, there is still room for improvement. First, there have been many methodologies and models developed or enhanced to investigate the effect mechanism of the drivers of climate regulation services via biogeochemical and biogeophysical process, while there are less researches that combine both the processes in the models; thus more research attention should be paid to the effect mechanisms that take both biogeochemical and biogeophysical effects into considerations. Second, in future research, improved models which can combine the effects of LUC and climate changes on the climate regulation as a whole should be developed. In addition, as human well-being changes along with the variation of climate regulation resulted from the effect of LUC and climate changes, further anthropogenic activities and economic development related with human well-being will respond to LUC and climate changes. However, there are relatively less researches that have taken the responses into consideration when assessing the effects, so future research should also focus on these potential societal responses.

\section{Conflict of Interests}

The authors declare that there is no conflict of interests regarding the publication of this paper.

\section{Acknowledgments}

This research was supported by China National Natural Science Funds for Distinguished Young Scholar (Grant no. 71225005), National Key Program for Developing Basic Science in China (Grant no. 2012CB955700), and Key Projects in the National Science \& Technology Pillar Program (Grant no. 2013BAC03B03).

\section{References}

[1] D. Schröter, W. Cramer, R. Leemans et al., "Ecology: ecosystem service supply and vulnerability to global change in Europe," Science, vol. 310, no. 5752, pp. 1333-1337, 2005.

[2] M. J. Metzger, M. D. A. Rounsevell, L. Acosta-Michlik, R. Leemans, and D. Schröter, "The vulnerability of ecosystem services to land use change," Agriculture, Ecosystems \& Environment, vol. 114, no. 1, pp. 69-85, 2006.

[3] R. F. Bangash, A. Passuello, M. Sanchez-Canales et al., "Ecosystem services in Mediterranean river basin: climate change impact on water provisioning and erosion control," Science of the Total Environment, vol. 458, pp. 246-255, 2013.

[4] S. N. Gosling, "The likelihood and potential impact of future change in the large-scale climate-earth system on ecosystem services," Environmental Science \& Policy, vol. 27, pp. S15-S31, 2013.

[5] X. Chen, J. Bai, X. Y. Li, G. P. Luo, J. L. Li, and B. L. Li, “Changes in land use/land cover and ecosystem services in Central Asia during 1990-2009," Current Opinion in Environmental Sustainability, vol. 5, no. 1, pp. 116-127, 2013.

[6] W. Reid, H. Mooney, A. Cropper et al., Ecosystems and Human Well-Being: Synthesis, Millennium Ecosystem Assessment, Island Press, Washington, DC, USA, 2005.

[7] P. Kumar, M. Verma, M. D. Wood, and D. Negandhi, Guidance Manual For the Valuation of Regulating Services, United Nations Environment Programme, 2010.

[8] J. P. Rodríguez, T. D. Beard Jr., E. M. Bennett et al., "Trade-offs across space, time, and ecosystem services," Ecology and Society, vol. 11, no. 1, article 28, 2006.

[9] S. R. Carpenter, E. M. Bennett, and G. D. Peterson, "Scenarios for ecosystem services: an overview," Ecology and Society, vol. 11, no. 1, article 29, 2006.

[10] W. J. Burroughs, Climate Change: A Multidisciplinary Approach, Cambridge University Press, Cambridge, UK, 2001.

[11] J. Houghton, Global Warming: The Complete Briefing, Cambridge University Press, Cambridge, UK, 2004.

[12] G. Bonan, Ecological Climatology: Concepts and Applications, Cambridge University Press, Cambridge, UK, 2nd edition, 2008.

[13] D. Fowler, K. Pilegaard, M. A. Sutton et al., "Atmospheric composition change: ecosystems-atmosphere interactions," Atmospheric Environment, vol. 43, no. 33, pp. 5193-5267, 2009.

[14] G. C. Nelson, E. Bennett, A. A. Berhe et al., "Drivers of change in ecosystem condition and services," in Ecosystems and Human Well-Being: Scenarios:Findings of the Scenarios Working Group, Island Press, Washington, DC, USA, 2005.

[15] N. Ash, N. Lucas, P. Bubb et al., "Framing the link between development and ecosystem services," in Ecosystem Services: A Guide for Decision Makers, World Resouces Institute, Washington, DC, USA, 2008.

[16] W. Jonathan, T. Megan, H. A. Louise et al., "The drivers of change in UK ecosystems and ecosystem services," UK National Ecosystem Assessment Technical Report 2011, UNEP-WCMC, Cambridge, UK.

[17] K. J. Anderson-Teixeira, P. K. Snyder, T. E. Twine, S. V. Cuadra, M. H. Costa, and E. H. Delucia, "Climate-regulation services of natural and agricultural ecoregions of the Americas," Nature Climate Change, vol. 2, no. 3, pp. 177-181, 2012.

[18] P. Smith, A. Mike, H. Black et al., "Regulating services," UK National Ecosystem Assessment Technical Report 2011, UNEPWCMC, Cambridge, UK, 2011. 
[19] A. D. McGuire, S. Sitch, J. S. Clein et al., "Carbon balance of the terrestrial biosphere in the twentieth century: analyses of $\mathrm{CO}_{2}$, climate and land use effects with four process-based ecosytem models," Global Biogeochemical Cycles, vol. 15, no. 1, pp. 183-206, 2001.

[20] R. Lal, "Soil carbon sequestration impacts on global climate change and food security," Science, vol. 304, no. 5677, pp. 1623$1627,2004$.

[21] S. Solomon, D. H. Qin, M. Manning et al., Climate Change 2007: The Physical Science Basis, Cambridge University Press, Cambridge, UK, 2007.

[22] R. Lal, "Soil carbon sequestration to mitigate climate change," Geoderma, vol. 123, no. 1-2, pp. 1-22, 2004.

[23] E. Ellis and R. Pontius, Land-Use and Land-Cover Change, Encyclopedia of Earth, Environmental Information Coalition, National Council for Science and the Environment, Washington, DC, USA, 2007, http://www.eoearth.org/view/article/ $154143 /$.

[24] W. R. Emanuel, H. H. Shugart, and M. P. Stevenson, "Climatic change and the broad-scale distribution of terrestrial ecosystem complexes," Climatic Change, vol. 7, no. 1, pp. 29-43, 1985.

[25] K. C. Prentice and I. Y. Fung, "The sensitivity of terrestrial carbon storage to climate change," Nature, vol. 346, no. 6279, pp. 48-51, 1990.

[26] T. M. Smith, R. Leemans, and H. H. Shugart, "Sensitivity of terrestrial carbon storage to $\mathrm{CO}_{2}$-induced climate change: comparison of four scenarios based on general circulation models," Climatic Change, vol. 21, no. 4, pp. 367-384, 1992.

[27] J. S. Olson, J. A. Watts, and L. J. Allison, Carbon in Live Vegetation of Major World Ecosystems, Oak Ridge National Lab, Oak Ridge, Tenn, USA, 1983.

[28] P. Reidsma, T. Tekelenburg, M. van den Berg, and R. Alkemade, "Impacts of land-use change on biodiversity: an assessment of agricultural biodiversity in the European Union," Agriculture, Ecosystems \& Environment, vol. 114, no. 1, pp. 86-102, 2006.

[29] R. A. Houghton, J. E. Hobbie, J. M. Melillo et al., "Changes in the carbon content of terrestrial biota and soils between 1860 and 1980-a net release of $\mathrm{CO}_{2}$ to the atmosphere," Ecological Monographs, vol. 53, no. 3, pp. 235-262, 1983.

[30] R. A. Houghton and C. L. Goodale, "Effects of land-use change on the carbon balance of terrestrial ecosystems," Ecosystems and Land Use Change, vol. 153, pp. 85-98, 2004.

[31] R. A. Houghton, "Revised estimates of the annual net flux of carbon to the atmosphere from changes in land use and land management 1850-2000," Tellus, Series B, vol. 55, no. 2, pp. 378390, 2003.

[32] R. A. Houghton and J. L. Hackler, "Changes in terrestrial carbon storage in the United States. I : the roles of agriculture and forestry," Global Ecology and Biogeography, vol. 9, no. 2, pp. 125$144,2000$.

[33] R. A. Houghton and J. L. Hackler, "Sources and sinks of carbon from land-use change in China," Global Biogeochemical Cycles, vol. 17 , no. 2 , pp. 3-1, 2003.

[34] R. A. Houghton, J. L. Hackler, and K. T. Lawrence, "The U.S. carbon budget: contributions from land-use change," Science, vol. 285, no. 5427, pp. 574-578, 1999.

[35] R. A. Houghton, "The annual net flux of carbon to the atmosphere from changes in land use 1850-1990," Tellus, Series B, vol. 51, no. 2, pp. 298-313, 1999.

[36] R. A. Houghton, J. D. Unruh, and P. A. Lefebvre, "Current land cover in the tropics and its potential for sequestering carbon," Global Biogeochemical Cycles, vol. 7, no. 2, pp. 305-320, 1993.
[37] R. A. Houghton, J. L. Hackler, and R. M. Cushman, Carbon Flux to the Atmosphere from Land-Use Changes: 1850 to 1990, Carbon Dioxide Information Center, Environmental Sciences Division, Oak Ridge National Laboratory, 2001.

[38] R. S. DeFries, R. A. Houghton, M. C. Hansen, C. B. Field, D. Skole, and J. Townshend, "Carbon emissions from tropical deforestation and regrowth based on satellite observations for the 1980s and 1990s," Proceedings of the National Academy of Sciences of the United States of America, vol. 99, no. 22, pp. 14256-14261, 2002.

[39] R. S. DeFries, C. B. Field, I. Fung, G. J. Collatz, and L. Bounoua, "Combining satellite data and biogeochemical models to estimate global effects of human-induced land cover change on carbon emissions and primary productivity," Global Biogeochemical Cycles, vol. 13, no. 3, pp. 803-815, 1999.

[40] S. Sitch, B. Smith, I. C. Prentice et al., "Evaluation of ecosystem dynamics, plant geography and terrestrial carbon cycling in the LPJ dynamic global vegetation model," Global Change Biology, vol. 9, no. 2, pp. 161-185, 2003.

[41] P. E. Levy, A. D. Friend, A. White, and M. G. R. Cannell, "The influence of land use change on global-scale fluxes of carbon from terrestrial ecosystems," Climatic Change, vol. 67, no. 2-3, pp. 185-209, 2004.

[42] G. M. Woodwell, J. E. Hobbie, R. A. Houghton et al., "Global deforestation: contribution to atmospheric carbon dioxide," Science, vol. 222, no. 4628, pp. 1081-1086, 1983.

[43] Y. Pan, R. A. Birdsey, J. Fang et al., "A large and persistent carbon sink in the world's forests," Science, vol. 333, no. 6045, pp. 988993, 2011.

[44] R. A. Houghton, D. L. Skole, C. A. Nobre, J. L. Hackler, K. T. Lawrence, and W. H. Chomentowski, "Annual fluxes of carbon from deforestation and regrowth in the Brazilian Amazon," Nature, vol. 403, no. 6767, pp. 301-304, 2000.

[45] V. K. Arora, G. J. Boer, J. R. Christian et al., "The Effect of terrestrial photosynthesis down regulation on the twentiethcentury carbon budget simulated with the CCCma earth system model," Journal of Climate, vol. 22, no. 22, pp. 6066-6088, 2009.

[46] R. K. Dixon, S. Brown, R. A. Houghton, A. M. Solomon, M. C. Trexler, and J. Wisniewski, "Carbon pools and flux of global forest ecosystems," Science, vol. 263, no. 5144, pp. 185-190, 1994.

[47] S. Brown and A. E. Lugo, "The storage and production of organic matter in tropical forests and their role in the global carbon cycle," Biotropica, vol. 14, no. 3, pp. 161-187, 1982.

[48] J. M. Kimble, R. F. Follett, C. V. Cole, and R. Lal, The Potential of US Cropland to Sequester Carbon and Mitigate the Greenhouse Effect, Ann Arbor Press, Chelsea, Mich, USA, 1998.

[49] R. F. Follett, J. M. Kimble, and R. Lal, The Potential of U.S. Grazing Lands to Sequester Carbon and Mitigate the Greenhouse Effect, CRC Press, New York, NY, USA, 2001.

[50] J. J. C. Dawson and P. Smith, "Carbon losses from soil and its consequences for land-use management," Science of the Total Environment, vol. 382, no. 2-3, pp. 165-190, 2007.

[51] A. E. Lugo and S. Brown, "Management of tropical soils as sinks or sources of atmospheric carbon," Plant and Soil, vol. 149, no. 1, pp. 27-41, 1993.

[52] A. Ayanaba, S. B. Tuckwell, and D. S. Jenkinson, "The effects of clearing and cropping on the organic reserves and biomass of tropical forest soils," Soil Biology and Biochemistry, vol. 8, no. 6, pp. 519-525, 1976.

[53] J. S. Powers, "Changes in soil carbon and nitrogen after contrasting land-use transitions in northeastern Costa Rica," Ecosystems, vol. 7, no. 2, pp. 134-146, 2004. 
[54] N. A. Scott, K. R. Tate, D. J. Giltrap et al., "Monitoring land-use change effects on soil carbon in New Zealand: quantifying baseline soil carbon stocks," Environmental Pollution, vol. 116, no. 1, pp. S167-S186, 2002.

[55] R. Lal, "World soils and the greenhouse effect," IGBP Global Change Newsletter, vol. 37, pp. 4-5, 1999.

[56] P. Smith, J. U. Smith, D. S. Powlson et al., "A comparison of the performance of nine soil organic matter models using datasets from seven long-term experiments," Geoderma, vol. 81, no. 1-2, pp. 153-225, 1997.

[57] B. M. Shrestha, S. Williams, M. Easter, K. Paustian, and B. R. Singh, "Modeling soil organic carbon stocks and changes in a Nepalese watershed," Agriculture, Ecosystems \& Environment, vol. 132, no. 1-2, pp. 91-97, 2009.

[58] A. M. Dieye, D. P. Roy, N. P. Hanan, S. Liu, M. Hansen, and A. Toure, "Sensitivity analysis of the GEMS soil organic carbon model to land cover land use classification uncertainties under different climate scenarios in senegal," Biogeosciences, vol. 9, no. 2, pp. 631-648, 2012.

[59] A. K. Metherell, Century: Soil Organic Matter Model Environment: Technical Documentation: Agroecosystem Version 4.0, Colorado State University, 1993.

[60] G. Barančkov, J. Halas, M. Guttekova et al., "Application of RothC model to predict soil organic carbon stock on agricultural soils of Slovakia," Soil and Water Research, vol. 5, no. 1, pp. $1-9,2010$.

[61] R. Francaviglia, K. Coleman, A. P. Whitmore et al., "Changes in soil organic carbon and climate change-application of the RothC model in agro-silvo-pastoral Mediterranean systems," Agricultural Systems, vol. 112, pp. 48-54, 2012.

[62] P. L. Woomer, L. L. Tieszen, G. Tappan, A. Touré, and M. Sall, "Land use change and terrestrial carbon stocks in Senegal," Journal of Arid Environments, vol. 59, no. 3, pp. 625-642, 2004.

[63] P. L. Woomer, A. Touré, and M. Sall, "Carbon stocks in Senegal's Sahel transition zone," Journal of Arid Environments, vol. 59, no. 3, pp. 499-510, 2004.

[64] M. D. K. Leh, M. D. Matlock, E. C. Cummings, and L. L. Nalley, "Quantifying and mapping multiple ecosystem services change in West Africa," Agriculture Ecosystems \& Environment, vol. 165, pp. 6-18, 2013.

[65] R. A. Betts, "Offset of the potential carbon sink from boreal forestation by decreases in surface albedo," Nature, vol. 408, no. 6809, pp. 187-190, 2000.

[66] M. H. Costa and J. A. Foley, "Combined effects of deforestation and doubled atmospheric $\mathrm{CO}_{2}$ concentrations on the climate of Amazonia," Journal of Climate, vol. 13, no. 1, pp. 18-34, 2000.

[67] J. J. Feddema, K. W. Oleson, G. B. Bonan et al., "The importance of land-cover change in simulating future climates," Science, vol. 310, no. 5754, pp. 1674-1678, 2005.

[68] R. A. Pielke Sr., G. Marland, R. A. Betts et al., "The influence of land-use change and landscape dynamics on the climate system: relevance to climate-change policy beyond the radiative effect of greenhouse gases," Philosophical Transactions of the Royal Society A, vol. 360, no. 1797, pp. 1705-1719, 2002.

[69] P. C. West, G. T. Narisma, C. C. Barford, C. J. Kucharik, and J. A. Foley, "An alternative approach for quantifying climate regulation by ecosystems," Frontiers in Ecology and the Environment, vol. 9, no. 2, pp. 126-133, 2011.

[70] P. K. Snyder, C. Delire, and J. A. Foley, "Evaluating the influence of different vegetation biomes on the global climate," Climate Dynamics, vol. 23, no. 3-4, pp. 279-302, 2004.
[71] M. Carlson, J. Chen, S. Elgie et al., "Maintaining the role of Canada's forests and peatlands in climate regulation," Forestry Chronicle, vol. 86, no. 4, pp. 434-443, 2010.

[72] J. G. Charney, "Dynamics of deserts and drought in Sahel," Quarterly Journal of the Royal Meteorological Society, vol. 101, no. 428, pp. 193-202, 1975.

[73] V. D. Pope, M. L. Gallani, P. R. Rowntree, and R. A. Stratton, "The impact of new physical parametrizations in the Hadley Centre climate model: HadAM3," Climate Dynamics, vol. 16, no. 2-3, pp. 123-146, 2000.

[74] F. Kroll, F. Müller, S. Bell et al., "Peri-urbanland use relationships-strategies and sustainability assessment tools for urbanrural linkages," integreted project, 2009.

[75] T. E. Twine, C. J. Kucharik, and J. A. Foley, "Effects of land cover change on the energy and water balance of the Mississippi River basin," Journal of Hydrometeorology, vol. 5, no. 4, pp. 640-655, 2004.

[76] M. Liu, H. Tian, G. Chen, W. Ren, C. Zhang, and J. Liu, "Effects of land-use and land-cover change on evapotranspiration and water yield in China during 1900-2000," Journal of the American Water Resources Association, vol. 44, no. 5, pp. 1193-1207, 2008.

[77] X. Yang, L. Ren, V. P. Singh et al., "Impacts of land use and land cover changes on evapotranspiration and runoff at Shalamulun River watershed, China," Hydrology Research, vol. 43, no. 1-2, pp. 23-37, 2012.

[78] J. Shukla, C. Nobre, and P. Sellers, "Amazon deforestation and climate change," Science, vol. 247, no. 4948, pp. 1322-1325, 1991.

[79] G. B. Bonan, D. Pollard, and S. L. Thompson, "Effects of boreal forest vegetation on global climate," Nature, vol. 359, no. 6397, pp. 716-718, 1992.

[80] X. Z. Deng, C. H. Zhao, and H. M. Yan, "Systematic modeling of impacts of land use and land cover changes on regional climate: a review," Advances in Meteorology, vol. 2013, Article ID 317678, 11 pages, 2013.

[81] E. J. Ma, A. P. Liu, X. Li, F. Wu, and J. Y. Zhan, "Impacts of vegetation change on the regional surface climate: a scenario-based analysis of afforestation in Jiangxi Province, China," Advances in Meteorology, vol. 2013, Article ID 796163, 8 pages, 2013.

[82] R. J. Qu, X. L. Cui, H. M. Yan, E. J. Ma, and J. Y. Zhan, "Impacts of land cover change on the near-surface temperature in the North China Plain," Advances in Meteorology, vol. 2013, Article ID 409302, 12, pages, 2013.

[83] P. Friedlingstein, P. Cox, R. Betts et al., "Climate-carbon cycle feedback analysis: results from the C4MIP model intercomparison," Journal of Climate, vol. 19, no. 14, pp. 3337-3353, 2006.

[84] D. S. Schimel, B. H. Braswell, E. A. Holland et al., "Climatic, edaphic, and biotic controls over storage and turnover of carbon in soils," Global Biogeochemical Cycles, vol. 8, no. 3, pp. 279-293, 1994.

[85] M. U. Kirschbaum, "The temperature dependence of soil organic matter decomposition, and the effect of global warming on soil organic C storage," Soil Biology and Biochemistry, vol. 27, no. 6, pp. 753-760, 1995.

[86] E. G. Jobbágy and R. B. Jackson, “The vertical distribution of soil organic carbon and its relation to climate and vegetation," Ecological Applications, vol. 10, no. 2, pp. 423-436, 2000.

[87] S. Long, "Modification of the response of photosynthetic productivity to rising temperature by atmospheric $\mathrm{CO}_{2}$ concentrations: has its importance been underestimated?" Plant, Cell \& Environment, vol. 14, no. 8, pp. 729-739, 1991. 
[88] T. Ise and P. R. Moorcroft, "The global-scale temperature and moisture dependencies of soil organic carbon decomposition: an analysis using a mechanistic decomposition model," Biogeochemistry, vol. 80, no. 3, pp. 217-231, 2006.

[89] D. S. Jenkinson, D. E. Adams, and A. Wild, "Model estimates of $\mathrm{CO}_{2}$ emissions from soil in response to global warming," Nature, vol. 351, no. 6324, pp. 304-306, 1991.

[90] E. D. Schulze and A. Freibauer, "Environmental science: carbon unlocked from soils," Nature, vol. 437, no. 7056, pp. 205-206, 2005.

[91] C. Fang, P. Smith, J. B. Moncrieff, and J. U. Smith, "Similar response of labile and resistant soil organic matter pools to changes in temperature," Nature, vol. 433, no. 7021, pp. 57-59, 2005.

[92] C. Fang, P. Smith, J. B. Moncrieff, and J. U. Smith, "Corrigendum: Similar response of labile and resistant soil organic matter pools to changes in temperature," Nature, vol. 436, no. 7052, p. $881,2005$.

[93] W. Knorr, I. C. Prentice, J. I. House, and E. A. Holland, "Longterm sensitivity of soil carbon turnover to warming," Nature, vol. 433, no. 7023, pp. 298-301, 2005.

[94] J. Sanderman, R. G. Amundson, and D. D. Baldocchi, "Application of eddy covariance measurements to the temperature dependence of soil organic matter mean residence time," Global Biogeochemical Cycles, vol. 17, no. 2, pp. 30-1, 2003.

[95] P. Dalias, J. M. Anderson, P. Bottner, and M.-M. Coûteaux, "Long-term effects of temperature on carbon mineralisation processes," Soil Biology and Biochemistry, vol. 33, no. 7-8, pp. 1049-1057, 2001.

[96] E. A. Davidson and I. A. Janssens, "Temperature sensitivity of soil carbon decomposition and feedbacks to climate change," Nature, vol. 440, no. 7081, pp. 165-173, 2006.

[97] M. Albani, D. Medvigy, G. C. Hurtt, and P. R. Moorcroft, "The contributions of land-use change, $\mathrm{CO}_{2}$ fertilization, and climate variability to the Eastern US carbon sink," Global Change Biology, vol. 12, no. 12, pp. 2370-2390, 2006.

[98] X. Xu, W. Liu, and G. Kiely, "Modeling the change in soil organic carbon of grassland in response to climate change: effects of measured versus modelled carbon pools for initializing the Rothamsted carbon model," Agriculture, Ecosystems \& Environment, vol. 140, no. 3-4, pp. 372-381, 2011.

[99] J. Zhan, H. Yan, B. Chen, J. Luo, and N. Shi, "Decomposition analysis of the mechanism behind the spatial and temporal patterns of changes in carbon bio-sequestration in China," Energies, vol. 5, no. 2, pp. 386-398, 2012.

[100] M. Jung, M. Reichstein, P. Ciais et al., "Recent decline in the global land evapotranspiration trend due to limited moisture supply," Nature, vol. 467, no. 7318, pp. 951-954, 2010.

[101] H. Bormann, "Sensitivity analysis of 18 different potential evapotranspiration models to observed climatic change at German climate stations," Climatic Change, vol. 104, no. 3-4, pp. 729-753, 2011.

[102] J. Lu, G. Sun, S. G. Mcnulty, and D. M. Amatya, "A comparison of six potential evapotranspiration methods for regional use in the southeastern United States," Journal of the American Water Resources Association, vol. 41, no. 3, pp. 621-633, 2005.

[103] P. Martin, N. J. Rosenberg, and M. S. McKenney, "Sensitivity of evapotranspiration in a wheat field, a forest, and a grassland to changes in climate and direct effects of carbon dioxide," Climatic Change, vol. 14, no. 2, pp. 117-151, 1989.
[104] M. S. Mckenney and N. J. Rosenberg, Simulating the Impacts of Climate Change on Potential Evapotranspiration: A Comparison of the Climate Sensitivity of Selected Methods, Resource for the Future, Washington, DC, USA, 1991.

[105] S. J. Reddy, "Sensitivity of some potential evapotranspiration estimation methods to climate change," Agricultural and Forest Meteorology, vol. 77, no. 1-2, pp. 121-125, 1995.

[106] J. Pastor and W. M. Post, "Response of northern forests to $\mathrm{CO}_{2}$ induced climate change," Nature, vol. 334, no. 6177, pp. 55-58, 1988.

[107] A. M. Solomon, “Transient response of forests to $\mathrm{CO}_{2}$-induced climate change: simulation modeling experiments in eastern North America," Oecologia, vol. 68, no. 4, pp. 567-579, 1986.

[108] J. T. Overpeck, D. Rind, and R. Goldberg, "Climate-induced changes in forest disturbance and vegetation," Nature, vol. 343, no. 6253, pp. 51-53, 1990.

[109] P. M. Cox, R. A. Betts, C. D. Jones, S. A. Spall, and I. J. Totterdell, "Acceleration of global warming due to carbon-cycle feedbacks in a coupled climate model," Nature, vol. 408, no. 6809, pp. 184$187,2000$.

[110] R. L. Peters and J. D. S. Darling, "The greenhouse effect and nature reserves," BioScience, vol. 35, no. 11, pp. 707-717, 1985.

[111] J. M. Melillo, "Vegetation/ecosystem modeling and analysis project: comparing biogeography and biogeochemistry models in a continental-scale study of terrestrial ecosystem responses to climate change and $\mathrm{CO}_{2}$ doubling," Global Biogeochemical Cycles, vol. 9, no. 4, pp. 407-437, 1995.

[112] R. A. Betts, P. M. Cox, S. E. Lee, and F. I. Woodward, "Contrasting physiological and structural vegetation feedbacks in climate change simulations," Nature, vol. 387, no. 6635, pp. 796799, 1997.

[113] R. G. Gallimore and J. E. Kutzbach, "Role of orbitally induced changes in tundra area in the onset of glaciation," Nature, vol. 381, no. 6582, pp. 503-505, 1996.

[114] S. Piao, P. Friedlingstein, P. Ciais, L. Zhou, and A. Chen, "Effect of climate and $\mathrm{CO}_{2}$ changes on the greening of the Northern Hemisphere over the past two decades," Geophysical Research Letters, vol. 33, no. 23, Article ID L23402, 2006.

[115] J. E. Lovelock and L. R. Kump, "Failure of climate regulation in a geophysiological model," Nature, vol. 369, no. 6483, pp. 732734, 1994.

[116] R. Costanza, R. D'Arge, R. De Groot et al., "The value of the world's ecosystem services and natural capital," Nature, vol. 387, no. 6630, pp. 253-260, 1997.

[117] R. C. Estoque and Y. Murayama, "Examining the potential impact of land use/cover changes on the ecosystem services of Baguio city, the Philippines: a scenario-based analysis," Applied Geography, vol. 35, no. 1-2, pp. 316-326, 2012.

[118] Z. F. Bian and Q. Q. Lu, "Ecological effects analysis of land use change in coal mining area based on ecosystem service valuing: a case study in Jiawang," Environmental Earth Sciences, vol. 68, no. 6, pp. 1619-1630, 2013.

[119] E. G. Mcpherson, "Environmental benefits and costs of the urban forest," in Proceedings of the 5th National Urban Forest Conference, pp. 52-54, 1992.

[120] J. F. Dwyer, E. G. Mcpherson, H. W. Schroeder, and R. A. Rowntree, "Assessing the benefits and costs of the urban forest," Journal of Arboriculture, vol. 18, pp. 227-227, 1992.

[121] P. C. Howard, The Economics of Protected Areas in Uganda: Costs, Benefits and Policy Issues, University of Edinburgh, 1995. 
[122] C. Corvalan, S. Hales, and A. J. McMichael, Mcmichael, Ecosystems and Human Well-Being: Health Synthesis, World Health Organization, 2005.

[123] N. A. Chappell, Y. D. Chen, J. Suhaimi, and M. Bonell, "Climate regulation of humid tropical hydrology," in Sustainable Hydrology for the 21st Century. Proceedings of the 10th BHS National Hydrology Symposium, pp. 172-177, British Hydrological Society, Exeter, UK, 2008.

[124] Y. D. Chen and N. A. Chappell, "Climate regulation of Southeast Asian hydrology," in Critical States: Environmental Challenges to Development in Monsoon Southeast Asia. Gerakbudaya, Kuala Lumpur, pp. 205-220, 2009.

[125] C. Rosenzweig, W. D. Solecki, L. Parshall, M. Chopping, G. Pope, and R. Goldberg, "Characterizing the urban heat island in current and future climates in New Jersey," Environmental Hazards, vol. 6, no. 1, pp. 51-62, 2005.

[126] P. Bolund and S. Hunhammar, "Ecosystem services in urban areas," Ecological Economics, vol. 29, no. 2, pp. 293-301, 1999.

[127] R. B. Richardson, "Ecosystem services and food security: economic perspectives on environmental sustainability," Sustainability, vol. 2, pp. 3520-3548, 2010.

[128] M. V. K. Sivakumar, H. P. Das, and O. Brunini, "Impacts of present and future climate variability and change on agriculture and forestry in the arid and semi-arid tropics," Climatic Change, vol. 70, no. 1-2, pp. 31-72, 2005.

[129] Q. Jiang, X. Deng, J. Zhan, and S. He, "Estimation of land production and its response to cultivated land conversion in North China Plain," Chinese Geographical Science, vol. 21, no. 6, pp. 685-694, 2011.

[130] Q. L. Shi, Y. Z. Lin, E. P. Zhang, H. M. Yan, and J. Y. Zhan, "Impacts of cultivated land reclamation on the climate and grain production in Northeast China in the future 30 years," Advances in Meteorology, vol. 2013, Article ID 853098, 8 pages, 2013.

[131] S. Lautenbach, C. Kugel, A. Lausch, and R. Seppelt, "Analysis of historic changes in regional ecosystem service provisioning using land use data," Ecological Indicators, vol. 11, no. 2, pp. 676687, 2011.

[132] R. Lal, R. F. Follett, B. A. Stewart, and J. M. Kimble, "Soil carbon sequestration to mitigate climate change and advance food security," Soil Science, vol. 172, no. 12, pp. 943-956, 2007.

[133] N. Gedney and P. J. Valdes, "The effect of Amazonian deforestation on the northern hemisphere circulation and climate," Geophysical Research Letters, vol. 27, no. 19, pp. 3053-3056, 2000.

[134] R. Lal and R. F. Follett, "Soil Carbon Sequestration and the Greenhouse Effect," ASA-CSSA-SSSA, 2009. 

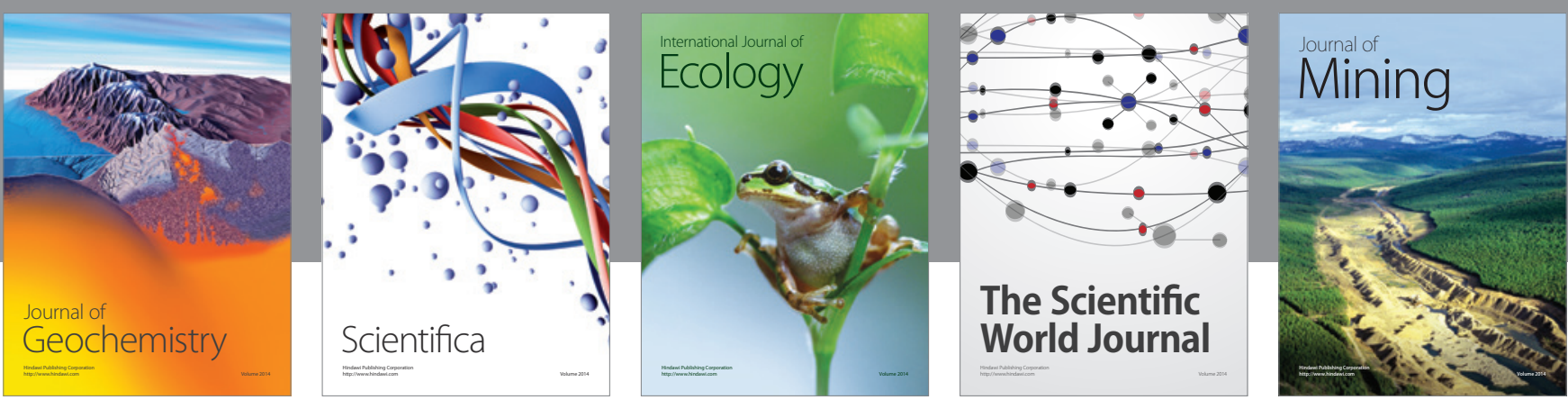

The Scientific World Journal
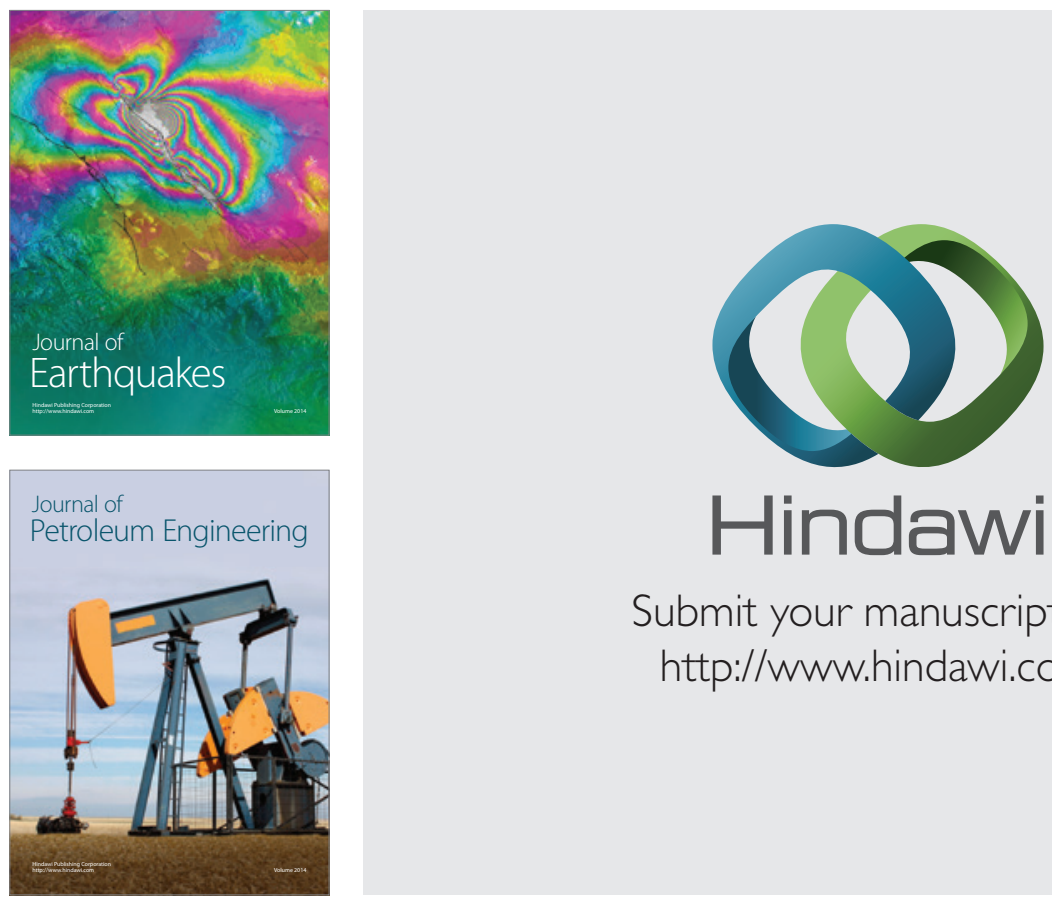

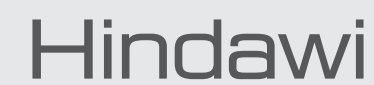

Submit your manuscripts at

http://www.hindawi.com
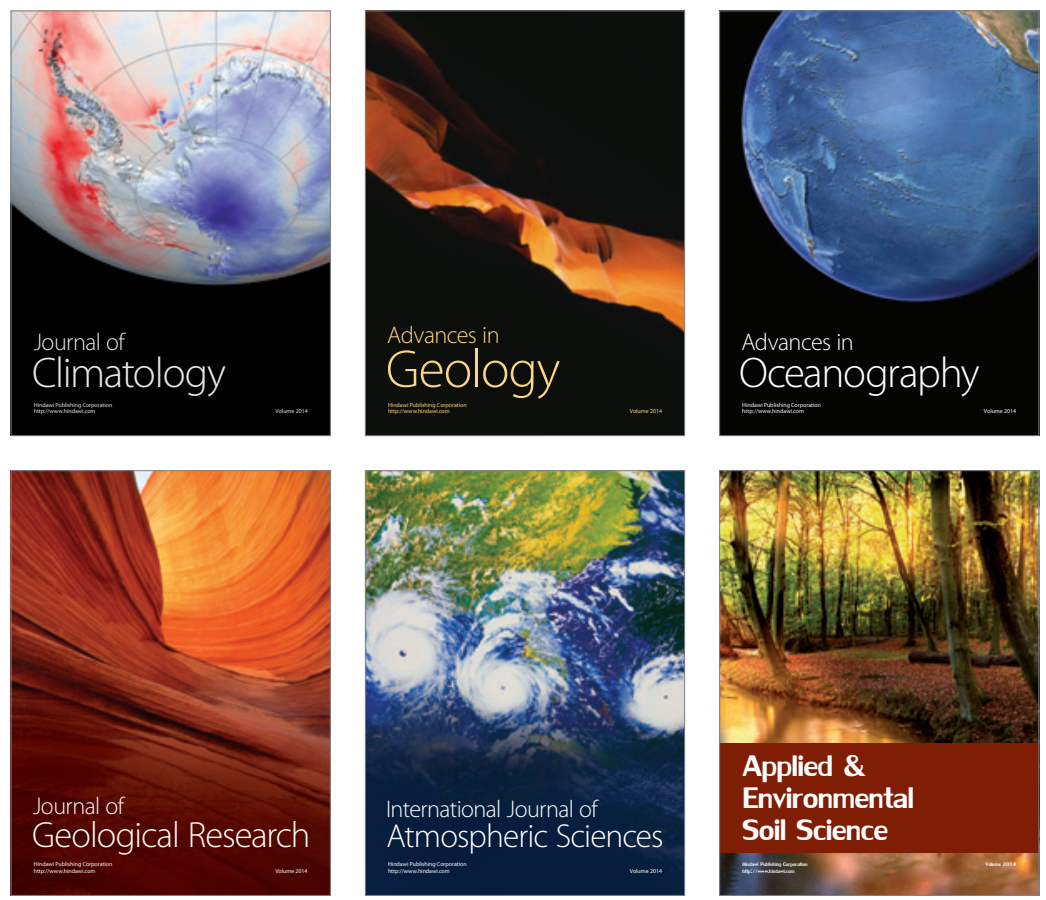
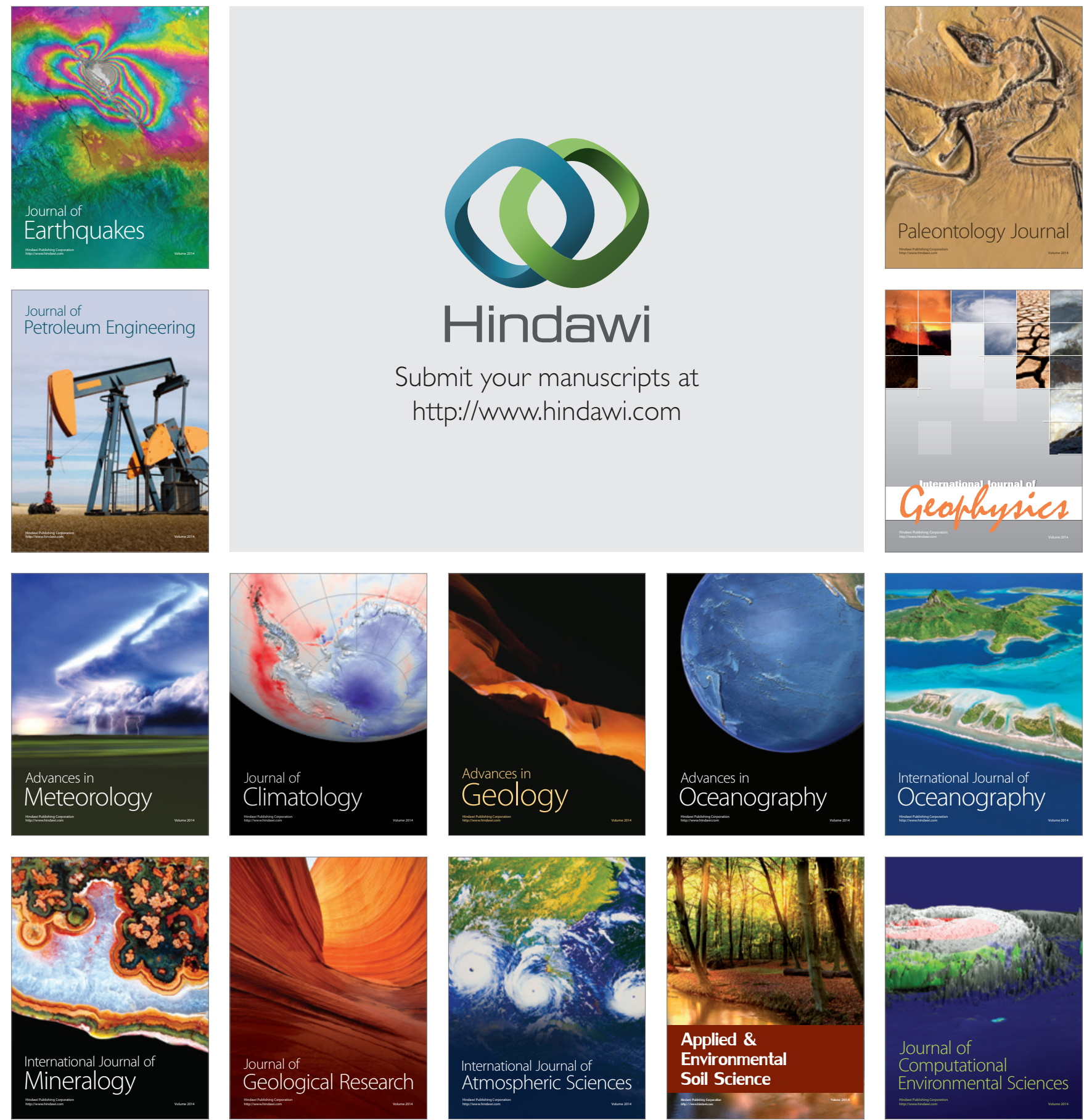